\title{
KEDAULATAN RAKYAT DAN DIALEKTIKA BERNEGARA DALAM KONTEKS KEINDONESIAAN
}

\author{
Mohammad Ryan Bakry \\ Universitas YARSI, Jakarta \\ mohammadryanbakry@gmail.com
}

Abstrak

Kedaulatan adalah basis utama eksistensi negara, dinamika dialektika bernegara akan menentukan bagaimana pola hubungan dialogis antara penguasa dengan rakyatnya dalam kerangka berbangsa dan bernegara. Artikel ini menganalisa pengertian, karakteristik dan jenis kedaulatan yang dihubungkan dengan dialektika sejarah kedaulatan Bangsa Indonesia. Fokus artikel ini adalah pada dimensi kontekstual kedaulatan, yakni eksistensi negara dalam bentuk implementasi kontinuitas program pembangunan di segala bidang. Diskursus hubungan dialogis antara penguasa dengan rakyat dalam kerangka kedaulatan bangsa Indonesia akan sangat relevan jika dikaitkan dengan argumentasi sejarah panjang Bangsa Indonesia. Eksplorasi tataran teoritik mengenai kedaulatan dan relevansinya dengan model kelembagaan dalam bangunan Bangsa dan Negara Republik Indonesia, akan disajikan dengan berbasis fakta sejarah evolusi kedaulatan dan hukum positif dalam konteks keindonesiaan. Kesimpulannya, bahwa dialetika sejarah kedaulatan Bangsa Indonesia telah menempatkan peran penting MPR dalam hal penentuan suatu haluan negara dalam garis-garis besar, untuk menjaga rangkaian kontinuitas program pembangunan di segala bidang, agar tidak terdapat resistensi penerimaan dan kepatuhan dari rakyat yang dapat mengakibatkan penanda dentum (sound) dan nyata (visible) dari kedaulatan rakyat (hard popular sovereignty). Selanjutnya, adalah suatu urgensi untuk menempatkan MPR sebagai "" guardian of popular soverignty" dalam kerangka "Kedaulatan Hukum" Bangsa Indonesia, dengan konsekuensi logis perlu diatur kembali dalam perubahan konstitusi yang kelima untuk mengembalikan fungsi dan kewenangan MPR terkait GBHN.

Kata Kunci: Kedaulatan, Dialektika Sejarah Kedaulatan, Majelis Permusyarawatan Rakyat

\section{Abstract}

Sovereignty is the main basis for the existence of the state, the dynamics of dialectics of the state will determine how the pattern of dialogical relations between the ruler and the people in the framework of nation and state. The focus of this article is on the contextual dimension of sovereignty, namely the existence of the state in the form of implementation of continuity of development programs in all fields. The discourse of dialogical relations between the ruler and the people in the framework of the Indonesian nation's sovereignty will be very reliant if it is associated with the long history argument of the Indonesian Nation. The exploration of the theoretical level regarding sovereignty and its relevance to the institutional model in the building of the Nation and State of the Republic of Indonesia, will be presented with facts based on the history of the evolution of positive sovereignty and law in the context of Indonesianness. The conclusion, that dialetics of the history of Indonesian sovereignty has placed the important role of the $M P R$ in determining the direction of the state in outlines, to maintain the continuity of development programs in all fields, so that there is no resistance to acceptance and compliance from the people which can lead to a boom (sound) and visible from hard popular sovereignty. Furthermore, it is an urgency to put the MPR as a "guardian of popular soverignty" in the framework of the "Law of Sovereignty" of the Indonesian Nation, with the logical consequence that it needs to be rearranged in the fifth constitutional change to restore the MPR's functions and authorities regarding GBHN. Keywords: Sovereignty, Dialectics of the Histoiy of Sovereignty, People's Consultative Assembly

\section{Pendahuluan}

Kajian tentang kedaulatan telah banyak dilakukan oleh pakar, baik pakar asing maupun pakar hrdonesia. Garis besai- hasil kajian tersebut menunjukkan arti pentingnya kedaulatan bagi eksistensi 
negara. Secara konseptual dapat dikatakan bahwa karakteristik dan jenis kedaulatan akan selalu sejalan dengan dinamika dialektika bernegara, bahkan, akan menentukan bagaimana pola hubungan dialogis antara penguasa dengan rakyatnya dalam kerangka berbangsa dan bernegara. Secara perbandingan, karakteristik dan jenis kedaulatan memiliki benairg merah yang berbeda satu dengair lainnya, masingmasing model kedaulatan berevolusi berdasarkan dimensi kontekstual.

Keabsahan kedaulatan jika semata-mata didasarkan atas pilihan kepentingan penguasa yang sifatnya momentum, konsekuensi logisnya adalah sendi-sendi bangunan kedaulatan akan rapuh dan m.enimbulkan kesenjangan dalanr Iral rangkaian kontinuitas program pembangunan di segala bidang untuk mewujudkan rnjuan negara. Diskursus hubungan dialogis antara penguasa dengan rakyat dalam kerangka kedaulatan bangsa Indonesia akan sangat relevan jika dikaitkan dengan argumentasi sejarah panjang Bangsa Indonesia.

Membumikan kembali kedaulatan dalam 'konteks keindonesiaan adalah suatu urgensi titik balik pembangunan Bangsa dan Negara Republik Indonesia. Oleh karena itu, pada kesempatan ini dipandang signifikan unUik menganalisa pengeifian, karakteristik dan jenis kedaulatan yang dihubungkan dengan dialektika sejarah kedaulatan Bairgsa Indonesia, untuk selanjutnya bertujuan membumikan kembali Kedaulatan dalam Konteks Keindonesiaair. Dalam artikel ini juga akan dieksplorasi tataran teoritik mengenai kedaulatan yang relevan dengan model kelembagaan dalam bangunan Bangsa dan Negara Republik Indonesia secara kontekstual.

\section{Pengertian, Karakteristik dan Jenis Kedaulatan}

Kedairlatan adalah satu diantara konsep tei^enting dari ilmu politik modem, dalam Encyclopedia Britairnica "The concept of sovereign tone of the most controversial ideas in political scienceand international law - is closely related to the difficult concepts of state and government and of independence and democracy" (Anon., 2018). Menumt Bodin, "sovereignty i.s that pow ler which is neither temporary, nor delegated, nor subject to particular rules which is cannot alter, nor aswerable to any otlrerpower on earth"। 2005), sehingga dapat dikatakan bahwa kedaulatan menjadi identitas penting negara yang membedakan dengan organisasi-organisasi lainnya. Secara terminologi makna kedaula'tan adalah berasal dari baliasa latin yakni superanus yang berarti kekuasaan teifinggi, jadi dapat dikatakan bahwa kedaulatan adalah kekuasaan tertinggi yang dimiliki oleli negara. John W. Burgess dalam bukunya "Political Science and Comparative Constitutional Law", krpAfl kki "... the sovereignty? I understand by it original, absolute, unlimited, universal power over individual subject and over al.1 associations of subjects",

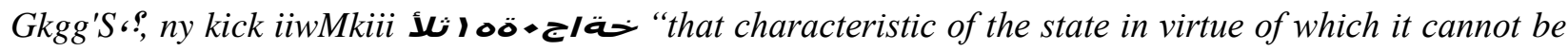
legally bound except by 'its own will, or limited by any other power than itself' (Sharma, 2007). Pollock memberikan argumentasi baliwa ", 'sovereignty is that power which is neither temporary not delegated, not subject to particular rules, whic.h it cannot alter, nor answerable to any other power on earth" (Sharma, 2007). Selanjutnya, Duguit 
memaknai kedaulatan sebagai "sovereignty is the commanding power of state, it is the will of nation organized in state; it is the right to give unconditional order to all individuals in the territory of the state (Sharma, 2007)

Edward Jenkins mendefinisikan kedaulatan dari sisi perihal kekuasaan yakni (Jenkins, 1900):

Somewhere or another, in all communities of this type, there resides an authority which, in the last resort, controls absolutely and beyond appeal the actions of every individual member of the community. No doubt, as has been well pointed out this sovereign power recognize certain moral of its action; it proceeds, in fact, at the risk of subject to ites control

Pada setiap diorama negara, maka akan selalu ada kekuasaan yang "memerintah dan memaksa" dan kekuasaan ini pada hakikatnya tanpa pembanding, sehingga kekuasaan ini dinamakan kedaulatan.

Kekuasaaan tertinggi dalam arti bahwa secara internal memiliki kuasa atas semua natural person dan legal person dalam negara, tidak ada satupun memiliki kompetensi untuk bertindak inkonsisten terhadap keinginan kedaulatan dalam negara. Pada titik ekstrem dapat dikatakan tidak ada satupun negara yang mengakui hak kedaulatan natural person atau legal person untuk dimiliki dalam teritorialnya. John W. Burgess berpendapat bahwa: (Burgess, 1890)

"the unlimited sovereignty of the state is not hostile to individual liberty, but its source and support...it its tme that the sovereign state may confer liberty upom some and not upon others, or more liberty upon some than upon others. But it is also true that no state has shown so little disposition to do this, and that no state has made liberty so full and general

Kekuasaan tertinggi dalam arti secara eksternal adalah negara lain dan organisasi internasional tidak memiliki kekuasaaan hukum untuk mencabut kepatuhan dari negara yang memiliki kedaulatan, bahkan instrumen hukum internasional maupun peijanjian internasional tidak mengikat suatu kedaulatan negara tanpa keinginan dari kedaulatan itu sendiri. Sejalan dengan argumentasi yang disampaikan oleh John W. Burgess (Burgess, 1890):

Power cannot be sovereign if it be limited; that which imposes the limitation is sovereign; and not until we reach the power which is unlimited, or only self-limited, have we attained the sovereignty. Those who hold the idea of a limited sovereignty? (which, I contend, is a contradictio in adjecto) do not indeed assert a real legal limitation, but a limitation by the laws of God, the laws of nature, the laws of reason, the laws between nation. But who is interpret, in last instance, these principles, which are termed laws of God, laws of nature, laws of reason, and laws between nations, when they are invoked by anybody in justification of disobedience to command the state, or of the powers which state authorize? Is it not evident that this must be the state its self?

Karakteristik istimewa dari kedaulatan disampaikan oleh Habiburrahman yakni permanence, exclusiveness, all comprehensiveness, inalienability, indivisibility, dan absolutenes (Rahman, 1971). Penjelasannya adalah sebagai berikut: Pertama, kedaulatan bersifat permanen dan terus tidak tergoyahkan selama negara berdiri. Pemerintahan dapat berganti, tetapi negara akan tetap ada, demikian pula dengan kedaulatan; Kedua, kedaulatan bersifat eksklusif yang dapat secara hukum memerintahkan ketaatan terhadap

natural person atau legal person, seliingga tidak dimungkinkan terdapat dua kedaulatan dalam satu negara, sebab bertentangan dengan kesatuan negara dan mengakui "imperium in imperio " atau negara dalam negara; Ketiga, kedaulatan bersifat universal dan berdaya ikat ruang dan waktu terhadap natural person atau legal person; Keempat, kedaulatan tidak dapat dikesampingkan, karena bersifat melekat pada negara sebagai satu kesatuan; Kelima, kedaulatan tidak terbagi, sehingga dapat dikatakan pembagian tersebut adalah kehancuran negara; Keenam, sifat utama dari kedaulatan adalah absolut bukan menjadi subjek dari hukum manapun, sehingga dapat dikatakan tidak memiliki limitasi. 
Ilmu politik modem membedakan jenis kedaulatan menjadi (Rahman, 1971) : Pertama, titular sovereignty yakni kedaulatan yang didesain untuk sistem monarki. Raja memilki kedaulatan yang bersifat permanence, exclusiveness, all comprehensiveness, inalienability, indivisibility, dan absolutenes; Kedua, legal soveregnty, yakni jenis kedaulatan yang menurut Hafiz Habibur Rahman "it can adjudge an infant of full age, it may attain man of reason after death; it may legitimise an illegitimate child. Or if it sees fit, make a mand a judge in his own case". (Rahman, 1971); Ketiga, political soveregnty, memiliki pengertian bahwa keseluruhan pengaruh didalam negara yang berdiri dibelakang kedaulatan hukum dan mengontrolnya. Menurut Hafiz Habibur Rahman, tidak direkognisi oleh hukum, tidak terorganisir dan tidak memungkinkan untuk mengekspresikan kehendak negara dalam bentuk perintah, tetapi tetap sebagai mandat yang kedaulatan hukum hams ikuti dan terikat; Keempat, popular sovereignty, adalah jenis lain dari kedaulatan, penggunaan ke frasa ini bukan dalam pengertian ilmu pengetahuan (scientific), namun digunakan secara sederhana untuk menunjukkan kekuasaan rakyat terhadap kekuasaan raja atau kelaskelas penguasa ('ruling class). Secara faktual berarti kemerdekaan politik, kontrol rakyat terhadap terhadap pemerintah dan hak rakyat untuk diberdayagunakan. Lord Bryce menyatakan bahwa kedaulatan rakyat sebagai basis dan tolok ukur dari demokrasi (Bryce, 1921).

Selanjutnya, adalah suatu urgensi untuk mengkaji kedaulatan secara de facto dan de jure yang tentu saja menjadi operational basis dari kedaulatan. Kedaulatan secara de facto adalah natural person atau legal Person yang dapat menyatakan kehendaknya sejalan dengan hukum atau bertentang dengan hukum, hal ini memjuk pada kekuasaaan untuk memaksakan kehendak dan secara nyata memang ditaati. Selanjutnya, kedaulatan secara de jure adalah mengenai hukum, kedaulatan ini bekeija bukan hanya dengan kehendak secara fisik namun kehendak secara hukum sebagai hak untuk mengatur. Ketika kedaulatan de facto dan de jure inkonsisten satu sama lainnya, maka satu diantaranya hams hilang (diminished) atau terintegrasi menjadi satu kesatuan (coalese).

\section{Letak Kedaulatan Berdasarkan Evolusi Kedaulatan}

Berdasarkan pengertian, karakteristik dan jenis kedaulatan yang telah dijelaskan pada sub pembahasan sebelumnya, maka relevan untuk mengkaji letak kedaulatan pada masing-masing kedaulatan tersebut. Momentum pertama sebelum adanya dinamika perkembangan negara modem, kedaulatan pada hakikatnya adalah merupakan sebuah atribut yang melekat pada raja, bukan negara, kedaulatan dalam pengertian ini menempatkan sistem monarki sebagai implementasi kedaulatan raja, sehingga dapat dikatakan bahwa raja dan negara menjadi satu kesatuan.

Momentum kedua adalah ketika terjadi revolusi demokrasi modem yang menghancurkan kedaulatan raja untuk bergeser pada kedaulatan rakyat. Kedaulatan rakyat sesungguhnya dapat dilacak pada zaman stoik dan romawi, dimana cicero mengajarkan kekuasaaan politik terletak pada rakyat sebagai satu kesatuan dengan negara. Namun faktanya, tergeser dengan adagium bahwa - ¿ the will of the emperor has the force of law" yang berarti tidak memberikan mang kosong kepada rakyat.

Momentum ketiga adalah masa modem dimana kedaulatan rakyat "dihidupkan" kembali oleh gerakan anti-monarchis yang menyerang sistem absolutisme monarki dan mempertahankan kedaulatan rakyat berdasarkan basis hukum alam dan kontrak sosial. Menurut Hafiz Habibur Rahman, "the people of as an indeterminate mass cannot exercise sovereignty" (Rahman, 1971) yang bermakna bahwa opini publik yang tidak terorganisir bagaimanapun kuatnya bukan merupakan kedaulatan karena kedaulatan hanya dapat dimaknai sebagai sesuatu yang hukum telah tentukan sebagai hak untuk mengambil peran kehendak negara melalui mesin-mesin pemerintahan (soft popular sovereignty). Pada titik tertentu (hard popular sovereignty) maka kedaulatan rakyat dapat diartikan sebagai kekuatan besar yang memungkinkan suatu mekanisme "revolusi" terhadap penguasa yang sah dalam negara. 
Argumentasi menarik disampaikan oleh Hafiz Habibur Rahman bahwa "the sovereignty so the people, in fact, is in time of peace, nothing more than public opinian;in case of a contest, only the might of revolution —not a legal power but a revolt against the existing sovereign(Rahman, 1971) Merujuk pada pendapat ini, dapat ditarik dua hal penting yakni: Pertama, kedaulatan rakyat secara konseptual dapat menjadi basis pembantukan kedaulatan lainnya, dalam pengertian bahwa model kedaulatan raja, kedaulatan hukum dan kedaulatan politik. Argumentasinya bahwa model-model kedaulatan lainnya pada saat pembentukan awal membutuhkan justifikasi dan validitas dari kedaulatan rakyat dalam hal penerimaan dan kepatuhan; Kedua, kedaulatan rakyat secara faktual jika merujuk poin pertama, maka jika terdapat resistensi penerimaan dan kepatuhan model kedaulatan lainnya (kedaulatan raja, kedaulatan hukum dan kedaulatan politik) maka kedaulatan rakyat secara penuh dimungkinkan melaksanakan revolusi terhadap kedaulatan lainnya.

Perlu menjadi perhatian bahwa model kedaulatan raja, kedaulatan hukum dan kedaulatan politik membutuhkan otoritas penguasa dalam hal implentasi kedaulatannya yang oleh pakar-pakar politik merujuk pada tenninologi "person or body of persons", sedangkan kedaulatan rakyat bersifat diam (silent) dan tidak tampak (invinsible), namun pada kondisi tertentu memiliki dentum (sound) dan nyata (visible). Contoh: Revolusi Perancis 1789-1799 sebagai resistensi penerimaan dan kepatuhan kedaulatan raja \{titular soveregnty).

Letak Kedaulatan Pada Periodisasi Evolusi Kedaulatan

\begin{tabular}{|l|c|c|c|c|c|}
\hline \multirow{2}{*}{ Momentum } & \multicolumn{2}{c|}{ Periodisasi Evolusi Kedaulatan } & \multirow{2}{*}{ Letak Kedaulatan } \\
\cline { 2 - 5 } & Yunani Kuno & Romawi & Pertengahan & Modern & \\
\hline Aristotle "Politicsw & - & & & & Belum teridentifikasi \\
\hline $\begin{array}{l}\text { Roman Dictum "The Will of } \\
\text { Emperor Las the force of }\end{array}$ & - & & - & Titular \\
\hline
\end{tabular}




\begin{tabular}{|c|c|c|c|c|c|}
\hline law" & & & & & \\
\hline $\begin{array}{l}\text { Konflik antara Gereja, Negara } \\
\text { dan Feodalisme }\end{array}$ & - & - & 11 & » & $\begin{array}{c}\text { Titular (Raja, Gereja dan } \\
\text { Baron) }\end{array}$ \\
\hline Machiavelli "leprince" & & & & 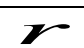 & Titular (teritorial) \\
\hline Bodin & & & & If & Hukum \\
\hline Hobbes "Leviatan" & & & & V & Titular \\
\hline $\begin{array}{l}k, k \leqq n \text { wo Treafies oj. } \\
\text { Government }\end{array}$ & & - & & 4 & Rakyat \\
\hline Rossoeu “Soda! Contracf & & & & 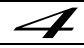 & Rakyat \\
\hline \begin{tabular}{|l} 
Austin Lecture on \\
Jurisprudence",
\end{tabular} & - & $»$ & - & ', & Hukum \\
\hline
\end{tabular}

Sumber: disarikan dari Hafiz Habibur Rahman

Tabel 1 menunjukan bahwa letak kedaulatan pada periodisasi evolusi kedaulatan berbeda satu dengan lainnya. Semenjak periodisasi romawi, pertengahan, modem (kecuali yunani kuno dengan keterbatasan fakta maka belum dapat terindentifikasi apakah terdapat konsep kedaulatan dalam pengertian yang sesungguhnya). Menjadi perhatian adalah pada momentum konflik antara gereja, negara dan feodalisme pada periodisasi pertengahan yang pada faktanya mengaburkan konsep titular sovereignty \Pengaburan dapat dijelaskan menjadi beberapa hal yang merajuk pada karaktestik kedaulatan \{permanence, exclusiveness, all comprehensiveness, inalienability, indivisibility, dan absolutenes) yakni kedaulatan bersifat permanen dan terus tidak tergoyahkan, dengan adanya pembagian kedaulatan antara gereja, raja dan feodalisme maka bertentangan dengan kesatuan negara dan mengakui "imperium in imperio" atau negara dalam negara. Sifat utama dari kedaulatan adalah absolut bukan menjadi subjek dari hukum manapun, sehingga dapat dikatakan tidak memiliki limitasi, pembagian kedaulatan gereja, raja dan feodalisme maka justru raja sebagai otoritas tunggal kedaulatan menjadi tidak konsisten atau dalam bahasa politik hanya pada tataran de jure.

\section{Dialetika Sejarah Kedaulatan Bangsa Indonesia}

Sejarah panjang bangsa Indonesia menjadi relevan untuk dikaji mengenai letak kedaulatan pada periodisasi evolusi kedaulatan. Didik Pradjoko dkk dalam penelitiannya mengungkapkan bahwa literatur penulisan sejarah di Indonesia sudah ada sejak masa kerajaan Hindu-Buddha berkembang di kepulauan Indonesi yakni "Pararaton", "Negara Kertagama", dan "Carita Parahiyangan". Selanjutnya, era kesultanan atau kesunanan yang bercorak Islam, terdapat "Hikayat Tanah Hitu", "Tuhfat al Nafls", "Babad Tanah Jawi", dan "Babad Kraton" (Pradjoko, 2008).

Terdapat beberapa kerajaan yang mewakili periodisasi awal sejarah bangsa Indonesia yakni: (Djoened, 1984) Pertama, kerajaan Kutai terletak di Kalimantan Timur, yaitu di hulu sungai Mahakam. Prasasti ditemukan terdapat pada tujuh buah tiang batu yang disebut dengan nama Yupa yang mempergunakan huruf Pallawa dan bahasa Sansekerta; Kedua, Kerajaan Tarumanegara berdasarkan penemuan dari beberapa prasasti tentang kerajaan Tarumanegara, maka letak kerajaan itu adalah di wilayah Jawa Barat, dengan pusat kerajaan terletak di sekitar daerah Bogor wilayah Jawa Barat; Ketiga, Kerajaan Melayu merupakan salah satu kerajaan yang berpusat di daerah Jambi, yaitu di tepi kanan- kiri Sungai Batanghari. Pada Sungai Batanghari ini ditemukan peninggalanpeninggalan

purba berupa candi-candi, arca, dan peninggalan lainnya; Keempat, Kerajaan Sriwijaya yang terletak pada sumetera bagian selatan di tepi sungai musi Kota Palembang dengan Prasasti Kedukan Bukit yang ditemukan di Bukit Siguntang, Prasasti Kota Kapur yang ditemukan di Pulau Bangka; Kelima, 
Kerajaan Mataram yang terletak di daerah Jawa Tengah Solo dengan bukti peninggalan yang tersebar di Gunung Lawu, Pegunungan Kendang, Gunung Lawu, Gunung Kidul; Keenam, Kerajaan Kediri dengan ibu kota Daha, berdasarkan situs-situs peninggalan yang tersebar di daerah Jawa Tengah; Ketujuh, Kerajaan Majapahit yang pernah berdiri dari sekitar tahun 1293 hingga 1500 Masehi dan berpusat di pulau Jawa bagian timur yang menguasai sebagian besar pulau Jawa, Madura, Bali, dan banyak wilayah lain di Nusantara. Kesamaan corak kedaulatan yang mewarnai ketujuh kerajaan di Indonesia adalah titular sovereignty dengan menempatkan raja sebagai pemangku kedaulatan.

Periodisasi sejarah bangsa Indonesia memiliki momentum penting, satu diantaranya adalah ketika masuk era kolonialisme Belanda. Penelitian yang dilakukan oleh Ulil Absiroh dkk bahwa Comelis De Houtman datang dari Belanda pada tahun 1956 yang mendarat di daerah Banten dan di ikuti pada tahun 1598 Van Neck dan Wybrecht Van Waerwyck di kepulauan Maluku pada bulan Maret 1599. Keberhasilan pelayaran berhasil mendorong berbagai perusahaan di Belanda untuk memberangkatkan kapalnya ke Indonesia ada 14 perusahaan yang telah memberangkatkan 62 kapal (Ulil Absiroh, 2017). Selanjutnya, diketahui bahwa hampir semua kepulauan di Nusantara dikuasai oleh Belanda melalui Perusahaan Hindia Timur Belanda atau Vereenigde Oostindische Compagnie (VOC). Konsekuensi logisnya adalah penerapan hukum Belanda di wilayah Nusantara demi menjaga stabilitas jalannya politik lcckusaaan VOC. Menurut Mardjono Rcksodiputro satu diantara hukum Belanda yang diterapkan di Indonesia adalah dalam bidang hukum pidana dengan terdapat pembagian tiga periode (Mardjono,2016):

(1) periode sampai tahun 1873, dimana golongan Bumiputera masih dapat tunduk kepada hukum pidana yang bersumber langsung pada hukum adat; dengan ketentuan bahwa untuk halhal tertentu (umumnya yang berhubungan dengan tatakelola pemerintahan dan perdagangan hasil bumi yang dikuasai pemerintah), secara tegas (uitdrukkelijk) dinyatakan berlaku ketentuan dalam "peraturan pemndang-undangan hukum pidana untuk golongan-golongan bumiputera" (strafrecht voor de Inheemsche groepen); (2) periode mulai tahun 1873, dimana terdapat dua KUHPidana, yaitu untuk golongan Bumiputera dan Timur Asing, dan yang lain untuk golongan Eropah. Ini dikenal sebagai sistem dualisme; (3) periode mulai tahun 1918, dimana ada sistem unifikasi dalam KUHPidana, yaitu berlakunya Wetboek van Strafrecht voor NederlandsIndie dalam tahun 1918, yang berlaku untuk semua golongan penduduk: Bumiputera (Indonesia), Timur Asing (Tionghoa dan Arab) dan Eropah (termasuk Jepang dan yang dipersamakan sebagai golongan Eropah). KUHPidana/WvS H-B ini, berdasarkan asas konkordansi, adalah serupa dengan WVS di Belanda yang mulai berlaku September 1886 di Belanda.

Kesamaan corak kedaulatan pada masa kolonialisme Belanda adalah legal Soverignty, yakni supremasi dalam bentuk hukum yang menentukan penguasa untuk menyatakan perintah tertinggi dan absolut negara. Penting untuk menjadi catatan penerapan hukum Belanda pada hakikatnya tidak sejalan dengan prinsip moral dan bahkan mandat opini dari 
Bangsa Indonesia, sebab segala bentuk penjajahan secara universal tidak pernah pernah mengedepankan nilai-nilai kemanusiaan, karena dialog dibangun senantiasa berbasis kekerasan dan tekanan kekuatan semata. Kembali kepada pendapat yang dikemukakan oleh Hafiz Habibur Rahman bahwa kedaulatan jenis ini (legal sovereignty) memungkinkan penguasa untuk mengenyampingkan hukum tuhan (divine law), prinsip moral dan bahkan mandat opini dari rakyat, karena tidak didasarkan atas penerimaan dan kepatuhan yang menjadi basis kedaulatan rakyat, atau dengan bahasa sederhananya "legal sovereignty" Kolonialisme Belanda tidak pernah diawali dan bersumber dari Kedaulatan Rakyat Bangsa Indonesia.

Kemerdekaan Negara Kesatuan Republik Indonesia pada tahun 1945, ditandai pergeseran kedaulatan hukum yang semula berada penguasa Kolonialisme Belanda menjadi kedaulatan rakyat Bangsa Indonesia. Kedaulatan rakyat bersifat diam isilent) dan tidak tampak (invinsible), namun pada kondisi tertentu memiliki dentum (sound) dan nyata (visible). Resistensi penerimaan dan kepatuhan kedaulatan hukum Kolonialisme Belanda, menjadikan kedaulatan rakyat bangsa Indonesia yang semula diam (silent) dan tidak tampak (invinsible), berubah menjadi dentum (sound) dan nyata \{visible). Undang-Undang Dasar Negara Republik Indonesia Tahun 1945 (UUD 1945) adalah merupakan bukti dialektika bernegara yang pada hakikatnya menempatkan Kedaulatan Rakyat sebagai basis pembentukan Kedaulatan Hukum dalam konteks ke Indonesiaan Negara Republik Indonesia. Konstitusi ini pula yang memberikan justifikasi dan validitas bangunan kenegaraan, beserta fungsi dan perannya kepada rakyat Indonesia.

UUD 1945 menentukan bentuk dan kedaulatan Negara Indonesia adalah Negara Kesatuan berbentuk Republik, dengan kedaulatan yang sepenuhnya dilakukan oleh Majelis Permusyawaratan Rakyat (MPR) yang bersumber dari kedaulatan rakyat. Kekuasaan Pemerintahan Negara menurut Pasal 4 UUD 1945 adalah dipegang oleh Presiden, untuk kekuasaan Legislatif menurut Pasal 19 ayat (1) dan (2) dipegang oleh Dewan Perwakilan Rakyat (DPR), dan kekuasan Yudikatif menurut Pasal 24 ayat (1) dipegang oleh Mahkamah Agung. Pembagian kekuasaan (division of power) Pemerintahan dalam arti luas menjadi cetak biru dimulainya kedaulatan hukum Bangsa Indonesia dalam kerangka Negara Indonesia.

\section{Membumikan Kedaulatan Rakyat dalam Konteks Keindonesiaan}

Satu diantara bangunan kenegaraan di Negara Republik Indonesia yang terbentuk atas dasar kedaulatan rakyat adalah Majelis Permusyarawaratan Rakyat (MPR) dan merupakan lembaga perwakilan yang pertama kali dibentuk dalam sejarah ketatanegaraan Bangsa Indonesia. Keberadaan MPR sebagai lembaga perwakilan yang pada awalnya terdiri atas anggota DPR ditambah dengan utusan-utusan dari daerah-daerah dan golongan- golongan. Fungsi dan kewenangan MPR adalah menetapkan Undang-Undang Dasar, Garis- Garis Besar Haluan Negara (GBHN), memilih Presiden dan Wakil Presiden, dengan mekanisme putusan MPR ditetapkan berdasarkan suara yang terbanyak.

Patut menjadi perhatian Pasal 1 ayat (2) Undang-Undang Dasar Negara Republik Indonesia, bahwa kedaulatan rakyat dilakukan sepenuhnya oleh MPR. Jika merujuk pada benang merah pemahaman letak kedaulatan berdasarkan evolusi kedaulatan, maka sesungguhnya: Pertama, momentum kemerdekaan tahun 1945 adalah bersumber dari "kedaulatan rakyat" bangsa Indonesia sebagai antitesis dari "kedaulatan hukum" belanda. 
Konsekuensi logisnya bahwa konstitusi sebagai kerangka dasar negara modern jika merujuk pada Undang-Undang Dasar Negara Republik Indonesia Tahun 1945, memiliki originalitasnya yang bersumber dari kedaulatan rakyat bangsa Indonesia; Kedua, Pasal 1 ayat (2) Undang-Undang Dasar Negara Republik Indonesia dapat pula dimaknai bahwa telah terbentuk "kedaulatan hukum Bangsa Indonesia" yang bersumber dari kedaulatan rakyat bangsa Indonesia. Tekstual konstitusi menempatkan MPR sebagai representasi kedaulatan rakyat dalam kerangka kedaulatan hukum Negara Indonesia yakni "kedaulatan rakyat dilakukan sepenuhnya oleh MPR" dalam Pasal 1 ayat (2).

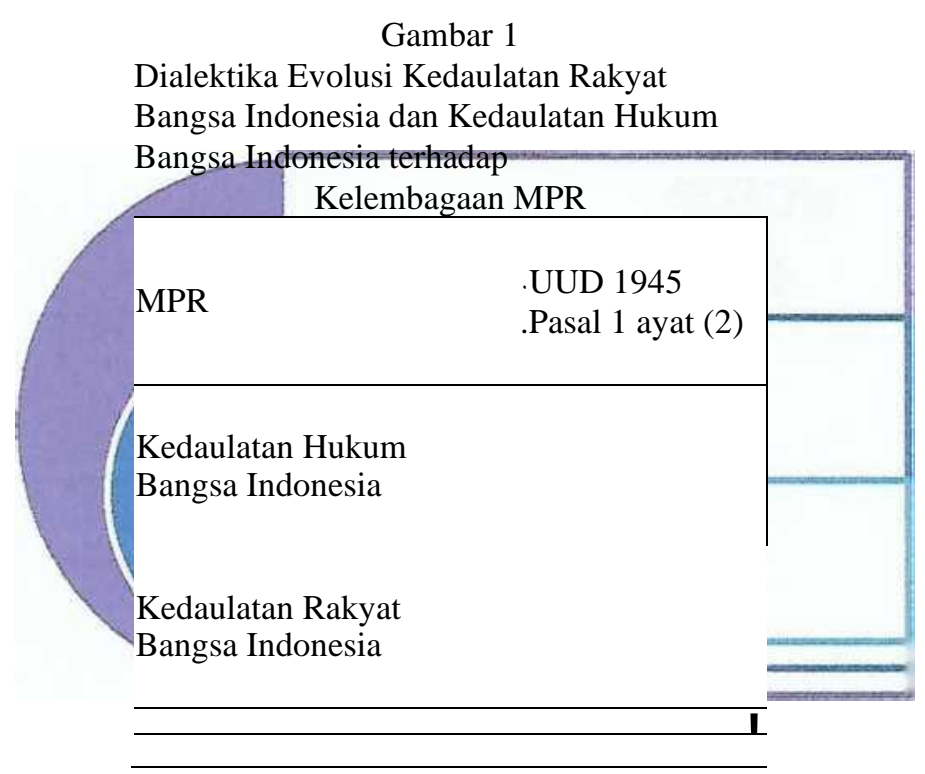

MPR sebagai "lembaga yang mewakili kedaulatan rakyat", berdasarkan kedaulatan hukum adalah benar adanya karena jelas diatur dalam konstitusi (de jure). Namun secara de facto terdapat inkonsistensi pemahaman mengenai kedaulatan rakyat khususnya karakter diam (silent) dan tidak terlihat (invincible) jika dihubungkan dengan kelembagaan MPR. Justru ketika kedaulatan rakyat itu memiliki dentum (sound) dan nyata (visible) maka harus diartikan bahwa terdapat resistensi penerimaan dan kepatuhan rakyat yang pada akhirnya pada titik tertentu dapat menimbulkan "revolusi" (hardpopular sovereignty). Sejarah telah mencatat bahwa revolusi perancis 1789-1799 adalah bukti empiris ketika kedaulatan rakyat memiliki dentum dan nyata. Menurut hemat penulis, apakah lebih baik dan lebih konsisten jika MPR mewakili kedaulatan hukum bangsa Indonesia, karena kedaulatan hukum memang harus terlembagakan sebagai person atau body of persons sebagai konsekuensi agar kehendak negara dapat berjalan.

Pada masa berlakunya kedaulatan hukum bangsa Indonesia, maka kedaulatan rakyat akan berkarakter diam (silentj dan tidak terlihat (invincible), MPR memiliki fungsi krusial yang secara filosofis yakni menjaga benang merah tujuan negara agar tetap sejalan pada konstitusi. Secara sederhana MPR menjadi "guardian of popular soverignty", dalam pengertian menjaga agar tetap dalam keadaan diam (silent) dan tidak terlihat (invincible), maksudnya adalah melindungi, memajukan kesejahteraan umum, mencerdaskan kehidupan bangsa dan ikut melaksanakan ketertiban dunia yang berdasarkan kemerdekaan, 
perdamaian abadi dan keadilan sosial dalam penyelenggaraan negara. Logikanya adalah negara dalam keadaan stabil maka kedaulatan rakyat akan silent dan invincible, hal ini sejalan dengan pendapat Hafiz Habibur Rahman" $/ 7 \mathrm{z}$ e sovereignty of people, in fact is, in time of peace, nothing more than public opinion; in case of a contest, only the might of revolution,- not a legal power but a revolt agains the existing sovereign " (Rahman, 1971)

Sebelum adanya amandemen UUD 45, satu diantara instrumen hukum mutakhir yang dimiliki oleh MPR sebagai lembaga tertinggi negara adalah GBHN, yakni suatu haluan Negara dalam garis-garis besar yang pada hakekatnya digunakan sebagai Pola Umum Pembangunan Nasional dan merupakan rangkaian kontinuitas program-program Pembangunan di segala bidang untuk dapat mewujudkan tujuan nasional. Hal tersebut sebagaimana teraiaktub dalam Pembukaan UUD 1945 yaitu melindungi segenap bangsa Indonesia dan untuk memajukan kesejahteraan umum, mencerdaskan kehidupan berbangsa dan ikut melaksanakan keteriban dunia yang berdasarkan kemerdekaan, perdamaian abadi dan keadilan sosial.

GBHN berfungsi memberikan kejelasan arah bagi perjuangan Negara dan rakyat Indonesia yang sedang membangun, agar dengan demikian dapat mewujudkan keadaan yang diinginkan lima tahun dalam rangkaian kontinuitas yang berjangka panjang. (Cahyono, 2017). Berdasarkan argumentasi tersebut diatas, maka dapat dikatakan GBHN merupakan instrumen hukum penting yang berfungsi untuk menjaga stabilitas Negara Indonesia.

Perubahan UUD 1945 pasca reformasi, menempatkan kelembagaan MPR yang semula sebagai lembaga tertinggi negara menjadi lembaga tinggi negara. Tugas dan kewenangan MPR pasca perubahan konstitusi menjadi lebih terbatas, diantaranya mengubah dan menetapkan UUD, melantik Presiden dan Wakil Presiden berdasarkan hasil pemilihan umum, memutuskan usul DPR berdasarkan putusan Mahkamah Konstitusi untuk memberhentikan Presiden dan atau Wakil Presiden dalam masa jabatannya, setelah Presiden dan atau Wakil Presiden diberi kesempatan menyampaikan penjelasan dalam Sidang Paripurna Majelis. Berikutnya, melantik Wakil Presiden menjadi Presiden apabila Presiden mangkat, berhenti, diberhentikan, atau tidak dapat melaksanakan kewajibannya dalam masa jabatannya; memilih dan melantik Wakil Presiden dari dua calon yang diajukan Presiden apabila terjadi kekosongan jabatan Wakil Presiden dalam masa jabatannya selambat-lambatnya dalam waktu enam puluh hari (Cahyono, 2017). Tidak ada lagi kewenangan MPR untuk mendengar dan membahas laporan kemajuan (progress report) dari lembaga negara dan pelaksanaan tugasnya; Ketiga, Presiden tidak perlu lagi memberi laporan pertanggungjawaban kepada MPR pada akhir masa jabatannya (Cahyono, 2017).

GBHN yang pada hakekatnya digunakan sebagai pola umum pembangunan nasional sebagai rangkaian kontinuitas program-program Pembangunan di segala bidang pasca pembahan konstitusi berpindah kepada Presiden sebagai Pemegang Kekuasaan Pemerintahan Negara. Berdasarkan hal tersebut, maka konsekuensi logisnya dimungkinkan terbukanya pintu diskontinuitas arah kebijakan pola pembangunan umum nasional. Maksudnya bahwa setiap Presiden yang terpilih, terbuka dan tidak terikat untuk memiliki pola umum pembangunan nasional yang berbeda dengan Presiden terdahulu. Dinamika ini justru menimbulkan kesenjangan dalam hal rangkaian kontinuitas program-program Pembangunan di segala bidang yang tentu saja membutuhkan perencanaan yang komprehensif. 
Pada titik tertentu (ihard popular sovereignty), tentu saja dinamika ini bisa "membangunkan" Kedaulatan Rakyat yang semula bersifat diam (silent) dan tidak tampak Cinvinsible), menjadi suatu dentum (sound) dan nyata (visible), jika diskontinuitas tersebut berakibat ketidakstabilan pada negara dalam pengertian tidak terlaksananya tujuan negara yakni melindungi segenap ban-gsa Indonesia dan unftrk memajukan kesejahteraan umum, mencerdaskan kehidttpan berbangsa dan ikut melaksanakan keteriban dttnia yang berdasarkan kemei'dekaan, perdamaian abadi dan keadilan sosial. Resistensi penerimaan dan kepatuhan rakyat akan menjadi penanda dentum (sound) dan nyata (visible) dari kedaulatan rakyat bangsa Indonesia yang secara hakikat bersifat permanence, exclusiveness, all comprehensiveness, inalienability,) indivisibility, Aiubsolutenes. Kesimpulan dan Saran

Rangkaian kontinuitas program pembangunan di segala bidang adalah untuk mevmjudkan tujuan negara dan menjaga stabilitasnya. Dialetika sejarah kedaulatan Bangsa Indonesia, telah menempatkan peran penting MPR dalam hal penenrtran suarti lraluan negara dalam garis-garis besar. Selanjutnya, sebagai "guardian of popular soverignty", maka MPR dalam kerangka "Kedaulatan Hukum" Bangsa Indonesia perlu diatur kembali dalam perubahan konstitusi yang kelima. Mengembalikan firngsi dan kewenangan MPR terkait GBHN adalah mertipakan suatu urgensi dalam koirteks unftrk menjaga rangkaian kontinuitas program pembangunan di segala bidang, agar tidak terdapat !.esistensi penei'imaan dan kepatuhan dari rakyat yang dapat mengakibatkair penanda deirtum (sound) dan nyata (visible) dari kedaulatan rakyat (hard popular sovereignty)

\section{Daftar Pustaka Buku}

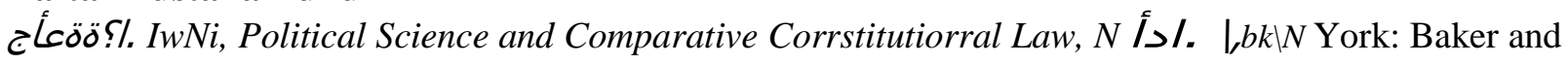
Taylot. Company, 1.890

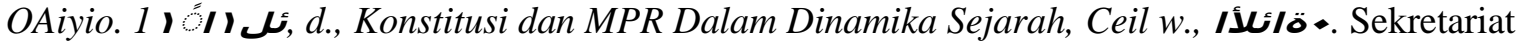
Jenderal MPR RI., 2017

Djoened. Marwati dkk. Sejarah Nasional Indonesia, Jakarta: Balai Pustaka, 1984 Jenkins. Edward, A Histoty of Politics, (Ne I v York: Macmillan. Co, 1900), P.151 VY؟६\%k>.eU, Modrd 1 Sejarah, Indonesia: Hibah. Modul Pendidikan Pengajaran:

Content Development Tema 2?7,Depok: Universitas Indonesia, 2008

Pru'thi. R.K, The Political Theory, New Delhi: Sarup \& Son, 2005

Rairman. Hafiz Habur, Political Science and Government, Eight Edition, Dacca: .Ideal Publication, 1971

Slrarma. Urmila and S.K. Sharma, Principles and Theory ofPolitical Science, Vol-1, New Delhi: Atlantic

Publisher. \& Distributors, 2007 Peraturan Perundang-Undangan

Undang-Undang Dasar Negar'a Republik Indonesia Talrun 1945 JurnaJ dan Makalah

Bryce. Lord, Political Science Quarterly, Vol. 36, No. 4 (Dec., 1921)

Reksodiputro. Mardjono, Beberapa Catatan Untuk Perjalanan Sejarah Hukum Pidana Indonesia, (makalah disampaikan sebagai Kuliah Tamu Pada Sekolah Tinggi Hukum Indonesia JENTER, Jakarta, 7 April 2016)

\section{Internet}

Ulil Absiroh et.al, Sejarah Pemahaman 350 Tahun Indonesia dijajah Belanda, file:///C:/Users/hp/Downloads/BAHAN ${ }^{<)}$20MPR/2054(S()-seiarah-pemahaman-350 tahun-indonesiadi.pdf di unduh pada tanggal 12 November 2018 Encyclopedia

Britannica,SovereigntyPo/\#zcs. https://www.britannica.com/topic/sQvereigntv, diunduh pada tanggal 11 November 201Sunarso, Hukum informasi Dan Transaksi Elektronik, Jakarta: Rineka Cipta, 2009 